Research paper

\title{
Counterbalancing work-related stress? Work engagement among intensive care professionals
}

\author{
Margo M.C. van Mol ${ }^{\mathrm{a}, *}$, \\ Marjan D. Nijkamp ${ }^{\text {b, }}$, \\ Jan Bakker ${ }^{\mathrm{a}, \mathrm{c}, \mathrm{d}, \mathrm{e}, 2}$, \\ Wilmar B. Schaufeli ${ }^{\mathrm{f}, \mathrm{g}}$, \\ Erwin J.O. Kompanje ${ }^{a, 2}$
}

a Department of Intensive Care Adults, Erasmus MC University Medical Center, Rotterdam, The Netherlands

${ }^{\mathrm{b}}$ Faculty of Psychology and Educational Sciences, Open University of the Netherlands, Heerlen, The Netherlands

${ }^{c}$ Division of Pulmonary, Allergy, and Critical Care, Columbia University College of Physicians and Surgeons/New York-Presbyterian Hospital, New York, NY, USA

d Department of Pulmonary and Critical Care, Langone Medical Center, New York University, New York, USA

e Department of Intensive Care, Pontificia Universidad Católica de Chile, Santiago, Chile

${ }^{\mathrm{f}}$ Research Unit Occupational and Organizational Psychology and Professional Learning, KU Leuven, Dekenstraat 2, 3000 Leuven, Belgium

${ }^{g}$ Department of Psychology, Utrecht University, Utrecht, The Netherlands

\section{A R T I C L E I N F O R M A T I O N}

\section{Article history:}

Received 21 October 2016

Received in revised form 5 May 2017

Accepted 9 May 2017

\section{Keywords:}

Empathy

ICU professionals

Personality

Well-being

Work engagement

Work-related stress

\begin{abstract}
A B S T R A C T
Background and objectives: Working in an Intensive Care Unit (ICU) is increasingly complex and is also physically, cognitively and emotionally demanding. Although the negative emotions of work-related stress have been well studied, the opposite perspective of work engagement might also provide valuable insight into how these emotional demands may be countered. This study focused on the work engagement of ICU professionals and explored the complex relationship between work engagement, job demands and advantageous personal resources.

Methods: This was a cross-sectional survey study among ICU professionals in a single-centre university hospital. Work engagement was measured by the Utrecht Work Engagement Scale, which included items about opinions related to the respondent's work environment. Additionally, 14 items based on the Jefferson Scale of Physician Empathy were included to measure empathic ability. A digital link to the questionnaire was sent in October 2015 to a population of 262 ICU nurses and 53 intensivists.

Results: The overall response rate was $61 \%(n=193)$. Work engagement was negatively related both to cognitive demands among intensivists and to emotional demands among ICU nurses. No significant relationship was found between work engagement and empathic ability; however, agreeableness, conscientiousness, and emotional stability were highly correlated with work engagement. Only the number of hours worked per week remained as a confounding factor, with a negative effect of workload on work engagement after controlling for the effect of weekly working hours.

Conclusion: Work engagement counterbalances work-related stress reactions. The relatively high workload in ICUs, coupled with an especially heavy emotional burden, may be acknowledged as an integral part of ICU work. This workload does not affect the level of work engagement, which was high for both intensivists and nurses despite the known high job demands. Specific factors that contribute to a healthy and successful work life among ICU professionals need further exploration.
\end{abstract}

(c) 2017 Australian College of Critical Care Nurses Ltd. Published by Elsevier Ltd. All rights reserved.

\footnotetext{
Abbreviations: ANCOVA, analysis of covariance; ICU, Intensive Care Unit.

* Corresponding author at: Department of Intensive Care Adults, Erasmus MC University Medical Center, P.O. Box 2040, Room 1005, 3000 CA Rotterdam, The Netherlands. E-mail addresses: m.vanmol@erasmusmc.nl (M.M.C. van Mol), marjan.nijkamp@ou.nl (M.D. Nijkamp), jan.bakker@erasmusmc.nl (J. Bakker), wilmar.schaufeli@kuleuven.be (W.B.Schaufeli), e.j.o.kompanje@erasmusmc.nl (E.J.O. Kompanje).

1 Open University of the Netherlands Faculty of Psychology and Educational Sciences, PO Box 2960, 6401 DL Heerlen, The Netherlands.

2 Erasmus MC University Medical Center, Department of Intensive Care Adults, PO Box 2040, Room H 625, 3000 CA Rotterdam, The Netherlands.
} 


\section{Introduction}

Working in an Intensive Care Unit (ICU) is increasingly complex and is also physically, cognitively and emotionally demanding. ${ }^{1-3}$ In addition to being confronted by end-of-life issues, ethical decision making, continuous human suffering, disproportionate care, miscommunication, and demanding family members, the ICU work environment has become increasingly technical. ${ }^{4}$ All these aspects require that ICU professionals maintain an extended skill-set (e.g., advanced life sustaining medical therapies, extended communication skills, and ethical deliberations). Furthermore, the changing perspective on healthcare (from provider-focused norms to personcentered care) often requires new competencies of ICU staff (e.g., shared decision-making). ${ }^{5}$ Increased demands, together with persistent work-related stress, reduce individual job satisfaction, and augment the risk of stress reactions, long-term absenteeism and burnout. ${ }^{6-8}$ This stress process could ultimately result in poor individual health and less successful working, leading to professionals leaving their jobs and impacting society due to lost economic investment. ${ }^{9-12}$

In a recent systematic literature review on emotional distress among ICU professionals it was suggested that the true magnitude of work-related stress, and burnout in particular, remains unclear due to a lack of unity in concepts and related measurements. ${ }^{4}$ Most research on work-related stress in ICUs has been directed at organizational and job-related factors. ${ }^{13}$ Although the negative emotions of work-related stress have been well studied, an opposite perspective might also provide valuable insight into how these emotional demands may be countered. Research is needed on the motivational processes which is affecting personal health positively. ${ }^{14-16}$ Work engagement is operationalized as a positive work-related state of mind and is characterized by vigour, dedication, and absorption. ${ }^{16,17}$ Vigour represents a high level of energy and mental resilience while working; dedication refers to experiencing a sense of significance, enthusiasm, and challenge; and absorption is characterized by being fully focused and absorbed in work. ${ }^{18}$ We explored in ICU professionals the relationship between work engagement and personal resources in the belief that a greater understanding might lead to interventions that positively affect personal health and promote a successful work life. Therefore, this study focused on the work engagement of ICU professionals in relation to personal resources.

\subsection{Study aims}

This study aimed to 1) explore how job resources and job demands are associated with work engagement, and 2) determine the advantageous personal resources required for work engagement. Based on previous findings, five hypotheses (Table 1) were formulated for work engagement ( 1 and 2$)^{18,19}$ and for personal resources (3, 3a, and $3 b) \cdot{ }^{20-22}$ The conceptual model is illustrated in Fig. 1.

\section{Methods}

The study adhered to the principles of the Declaration of Helsinki. The study does not fall under the Medical Research Involving Human Subjects Act (non-WMO research) and therefore an official approval of this study by the ethical committee was not required. ${ }^{23}$ The survey materials explained that by voluntary responding to the questions and mailing the survey back, the recipients had agreed to participate in the research.

\subsection{Study design}

The design of this study was a cross-sectional online survey study of ICU professionals at a single-centre university hospital with one of the largest adult ICUs in the Netherlands. A short introduction and a plain hyperlink to the tailored questionnaire were distributed in October 2015 to the work email addresses provided by ICU management. Data were gathered during four consecutive weeks. Weekly individual reminders and general feedback on the response rates were provided twice to encourage participation. To guarantee confidentiality, a strict separation of the research data and personal data files was maintained throughout the entire process.

\subsection{Study population}

The ICU setting under study contains 48 operational beds, divided into four units: two mixed units for neurological, neurosurgical, transplantation, general and trauma surgery, and medical patients; the cardio-thoracic surgery ICU; and the cardiology ICU. All professionals, i.e., 162 nurses/students in the mixed ICUs, 46 nurses/students in the thoracic ICU, 54 nurses/students in the cardiac ICU and 53 intensivists/medical doctors, who worked for at least $12 \mathrm{~h} /$ week ( 0.3 full time equivalent), were eligible to participate in the study. Professionals not regularly working in the ICU were excluded from the study.

\subsection{Measures}

The questionnaire used was based on a composite of existing validated reliable questionnaires and reflected the diverse concepts of interest. Most items on 'job demands' ( 9 items) and 'job resources' (21 items) stemmed from the Questionnaire on the Experience and Evaluation of Work ${ }^{24}$ and the National Working Conditions survey, ${ }^{25}$ both generally used in the Netherlands for psychosocial risk evaluation at work. ${ }^{16}$ The subscales showed high scale reliabilities, for example, 'social support' of coworkers with three items (e.g., 'Do you feel recognized and appreciated

Table 1

Study hypotheses.

1

3

3a

$3 \mathrm{~b}$

Job demands are negatively related to work engagement; when experiencing higher physical, cognitive and emotional demands the level of work engagement is decreased.

Job resources are positively related to work engagement; when experiencing higher team spirit, team efficacy, social support, autonomy, performance feedback, and better peer communication, the level of work engagement is increased.

Personal resources, i.e., personality traits and empathic ability, have main effects on work engagement; agreeableness, extraversion, conscientiousness, openness, and empathic ability have positive effects, neuroticism has a negative effect.

Personal resources have a moderating effect on the relationship of job demands and work engagement; having more favorable personal resources decreases the negative main effect of job demands on work engagement.

Personal resources have a moderating effect on the relationship of job resources and work engagement; having more favorable personal resources increases the positive main effect of job resources on work engagement. 


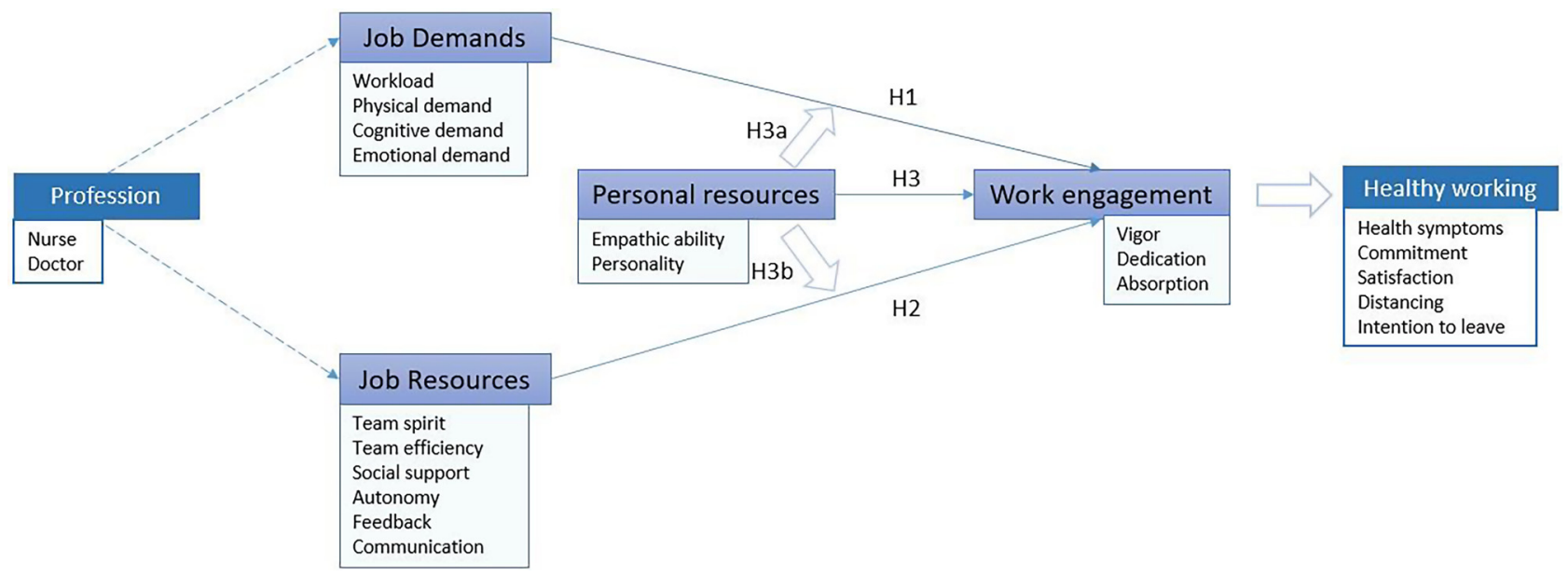

Fig. 1. Conceptual model.

by colleagues?') with $\alpha=0.85$, 'performance feedback' with three items (e.g., 'Do you get enough information about the results of your work?') with $\alpha=0.80$, and 'autonomy' with seven items (e.g., 'Do you have enough freedom and independence in your work?') with $\alpha=0.90$. The Revised NEO Personality Inventory, with 60 self-rated items on a five-point scale ( 1 = totally disagree; $5=$ totally agree), was added to measure the Big $\mathrm{V}$ personality traits: 'neuroticism', 'extraversion', 'openness', 'agreeableness', and 'conscientiousness'. ${ }^{26}$ The internal consistencies of the NEO-PI-R (the 60-item domain-only version) as reported in the manual were satisfactory (ranging from 0.79 to 0.83 ). Furthermore, the testretest reliability has been shown to suffice for all five dimensions. The Jefferson Scale of Physician Empathy was included in part, with 13 self-rated items on a five-point scale ( 1 =never; $5=$ always), to measure empathic ability in three subscales. ${ }^{27}$ 'Cognitive empathy' with five items (e.g., 'Understanding the feelings of patients and their relatives is important in caring'), 'emotional empathy' with six items (e.g., 'I do not allow myself to be affected by intense emotional relationships with patients or their relatives'), and 'perspectivetaking' with two items (e.g., 'It's hard for me to see things from the perspective of the patient or the patient's family'). All items related to empathy were rephrased and applied to the ICU environment and were thereafter pilot tested for comprehensiveness $(n=5)$ so that the professionals could better understand the statements provided. Neither the validity nor reliability of these adapted subscales has been established. Work engagement was measured using the Utrecht Work Engagement Scale with 17 self-rated items on a fivepoint scale ( 1 =never; $5=$ always $)$ in three subscales. ${ }^{28}$ Cronbach's alpha of 'vigour' ( 6 items, e.g., 'At work, I feel like I am bursting with energy') ranged between 0.81 and 0.90 , 'dedication' ( 5 items, e.g., 'I am enthusiastic about my job') ranged between 0.88 and 0.95 , and 'absorption' ( 6 items, e.g., 'I get carried away when I am working') ranged between 0.70 and 0.88 . Five items on sleeping quality, health quality and sickness absence were taken together to measure 'healthy state'. 'Successful working' (five items) was measured as satisfaction in work, team commitment, institute commitment, self-distancing, and intention to leave work. Although ordinal rating scales were used in all subscales, e.g., 'never' to 'always' with corresponding numbers one through five, these were considered as rational scales for the purpose of analyses. Previous studies have shown this method to be feasible, using parametric statistical tests to provide subgroup analyses and to compare with benchmarks. ${ }^{29}$ All items were in the Dutch language.

A representative study sample $(n=1213)$ of the Dutch working population was used as a benchmark. ${ }^{16}$ This benchmark reflected the total industry according to the classifications of the National Bureau of Statistics. The largest groups were 'health and welfare' (17.4\%), 'commercial services' (14.4\%), and 'retail and repair' (13.1\%). The employees in the general benchmark working in the 'health and welfare domain' acted as the benchmark for empathic ability.

\subsection{Data analysis}

The data were analyzed using IBM $^{\circledR}$ SPSS version 22 with the classical definition of $p<0.05$ applied for statistical significance. Descriptive statistics (means, standard deviations, and percentages) were calculated, reliability was tested with Cronbach's alpha. ${ }^{30}$ The relationships between the means of subscale scores as independent variables and work engagement as the outcome variable were analyzed by Pearson's (i.e., normally and linear distributed variables) and Spearman's (i.e., ordinal scale or non-normally distributed variables) correlation coefficients. Variable correlations below 0.3 were considered weakly associated, between 0.3 and 0.5 moderately associated, and between 0.5 and 1.0 strongly associated. ${ }^{30}$ Furthermore, linear regression models of work engagement as a function of potential personal and professional risk factors were constructed using a stepwise method. The total model was built after checking the assumptions of non-zero variance and multicollinearity of the variables, homoscedasticity from the graph of residual terms, and independent errors with the Durbin-Watson test. An analysis of covariance was performed (ANCOVA) to control the bias of confounding variables. To run the ANCOVA, workload was split into three categories based on frequencies (approximately 25\% low, 50\% middle and 25\% high workload). Two additional assumptions were checked: the independence of the covariate and the independent variable; and the homogeneity of regression slopes. ${ }^{30}$ Finally, moderation was tested with the PROCESS-tool.

\section{Results}

\subsection{Descriptive statistics and scale reliability}

The overall response rate was $61.3 \%(n=193)$ none of the returned questionnaires were excluded for reason of non-response on any item. Seven respondents were excluded from further analysis because of limited working hours ( $<12 \mathrm{~h}$ per week) or because they had an administrative or supporting staff occupation. Most respondents were female, ICU nurses, middle-aged, Dutch, college- 
Table 2

Demographic characteristics of respondents.

\begin{tabular}{|c|c|c|}
\hline & \multicolumn{2}{|c|}{ Respondents $(\mathrm{N}=193)$} \\
\hline & Count (\%) & Mean (St. dev) range \\
\hline \multicolumn{3}{|l|}{ Gender } \\
\hline Female & $132(68.4)$ & \\
\hline Male & $61(31.6)$ & \\
\hline \multirow[t]{2}{*}{ Age } & & 44.5 (11.79) \\
\hline & & $22-67$ \\
\hline \multicolumn{3}{|l|}{ Ethnic background } \\
\hline Dutch & $188(97.4)$ & \\
\hline Non-Dutch & $5(2.6)$ & \\
\hline \multicolumn{3}{|l|}{ Family situation } \\
\hline Families with children & $82(42.5)$ & \\
\hline Single with children & $6(3.1)$ & \\
\hline Married/living with partner & $68(35.2)$ & \\
\hline Single & $37(19.2)$ & \\
\hline \multicolumn{3}{|l|}{ Education } \\
\hline Non/primary school & $11(5.7)$ & \\
\hline GCSE & $11(5.7)$ & \\
\hline A-levels & $31(16.1)$ & \\
\hline College & $103(53.4)$ & \\
\hline University & $37(19.2)$ & \\
\hline \multicolumn{3}{|l|}{ Occupation } \\
\hline Nurse & $146(75.6)$ & \\
\hline Doctor & $32(16.6)$ & \\
\hline Other & $15(7.6)$ & \\
\hline \multirow[t]{2}{*}{ Working hours per week (contract) } & & $31.1(9.1)$ \\
\hline & & $0-48$ \\
\hline \multirow[t]{2}{*}{ Working hours per week (reality) } & & $33.6(11.7)$ \\
\hline & & $0-90$ \\
\hline \multirow[t]{2}{*}{ Years working in the ICU } & & $14.1(10.1)$ \\
\hline & & $1-41$ \\
\hline \multicolumn{3}{|l|}{ ICU team, working in } \\
\hline Cardio-thoracic surgery ICU & $29(15)$ & \\
\hline Mixed ICU, unit 1 & $41(21.2)$ & \\
\hline Mixed ICU, unit 2 & $44(22.8)$ & \\
\hline Cardiology ICU & $43(22.3)$ & \\
\hline All units & $36(18.7)$ & \\
\hline \multicolumn{3}{|l|}{ Health indication } \\
\hline Excellent & $10(5.2)$ & \\
\hline Very good & $49(25.4)$ & \\
\hline Good & $116(60.1)$ & \\
\hline Reasonably well & $17(8.8)$ & \\
\hline Poor & $1(.5)$ & \\
\hline \multicolumn{3}{|l|}{ Good sleeping quality } \\
\hline Disagree & $37(19.2)$ & \\
\hline Neutral & $32(16.6)$ & \\
\hline Agree & $124(64.3)$ & \\
\hline
\end{tabular}

level educated and living with a partner and children. Table 2 presents all background characteristics of the respondents. Across the four ICUs respondents showed similar characteristics, however, ICU nurses and intensivists differed in the male-female ratio $(0.39$ versus $1.13, \mathrm{p}<0.05$ ), educational level (mostly college versus all university, $\mathrm{p}<0.001$ respectively), mean 'number of years working in ICU' $(15.4 \pm 10.1$ versus $8.1 \pm 8.02, \mathrm{p}<0.001)$, and the mean 'overtime hours worked' ( $0.20 \pm 3.0$ versus $11.97 \pm 15.9)$.

The scale reliability, represented as Cronbach's $\alpha$, and the means of 'job demands', 'job resources', 'personal resources', 'work engagement', and 'healthy work' are shown in Table 3. The Cronbach's $\alpha$ values were 0.86 for 'vigour', 0.89 for 'dedication', and 0.82 for 'absorption', which indicated reliable subscales. Only 'emotional empathy' ( $\alpha=0.65)$ and the 'ICU-specific' subscale $(\alpha=0.58)$ showed limited internal consistency, while most other variables exceeded 0.70 .

\subsection{Independent variables: job demands and job resources}

The mean 'job demands' were $2.4( \pm 0.7), 2.9( \pm 0.6)$, and $2.5( \pm 0.6)$ for the physical, cognitive and emotional domains respectively (Table 3 ). These values exceeded the general Dutch benchmark, with $2.0,2.5$, and 1.8 , respectively. However, $89.7 \%$, $98.8 \%$, and $94.3 \%$ (respectively) of the participants reported rarely having problems with the physical, cognitive, and emotional demands. Only $3.1 \%$ of the respondents reported workload to be too high, which was considerably lower than the $3.6 \%$ reported by the benchmark.

As also shown in Table 3, the job resources of 'social support', 'communication', 'team efficacy', and 'team spirit' produced means amongst the ICU professionals that were similar to the benchmark, while for both 'performance feedback' $(2.3 \pm 0.7)$ and 'autonomy' ( $2.5 \pm 0.7)$ ICU professionals scored lower than the average for Dutch employees (2.7 and 2.9 respectively, non-significant). Respondents also showed near-equal scores on the cognitive component (3.9 compared to a 4.0 benchmark, non-significant) and a lower score on the emotional component (3.0 compared to 3.8 benchmark, $\mathrm{p}<0.05$ ) of 'empathy'.

\subsection{Outcome variables: work engagement and healthy work}

Regarding work engagement, ICU professionals scored similarly on 'vigour' $(3.5 \pm 0.7)$, higher on 'dedication' $(3.9 \pm 0.7)$ and lower on 'absorption' $(2.8 \pm 0.7)$ compared to the average Dutch employee (3.7, 3.5, and 3.4, respectively). Although the results for the intensivists and ICU nurses were broadly similar, a statistically significant higher mean for physical demand was observed in nurses. In addition, the nurses scored lower on dedication and absorption.

The same results were found for healthy work among intensivists and ICU nurses. Both professions reported few stress-related symptoms such as self-distancing, health complaints and sleeping disorders. Almost $55 \%$ of the respondents reported absenteeism in the past year, with a statistically significant difference of $60 \%$ for ICU nurses and 31\% for intensivists. Further details on absenteeism were not analysed because of high non-response rates to those particular items. Six percent of participants were planning to leave their job in the upcoming year.

\subsection{The effect of age, years of experience, and working hours}

The covariates of age and years of experience did not impact on work engagement. There was, however a negative effect of workload on work engagement after controlling for the effect of the number of hours worked per week $(F(1,179)=5.40, p=0.02,95 \%$ confidence interval $\left.[0.00 ; 0.02], \eta^{2}=0.03\right)$. The estimated means for the low, middle, and high workload were $3.49( \pm 0.08), 3.46( \pm 0.05)$, and $3.23( \pm 0.74)$, respectively.

\subsection{Hypothesis testing}

A weak negative correlation was found for total 'job demands' and 'work engagement' $(r=-0.20, \mathrm{p}<0.01)$ for all respondents combined. However, the 'cognitive demands' for intensivists only $(r=-0.46, \mathrm{p}<0.001)$ and the 'emotional demands' for ICU nurses only $(r=-0.27, \mathrm{p}<0.001)$ were moderately and weakly related (respectively) to 'work engagement'. Moderately positive correlations between 'job resources' and 'work engagement' were found for 'team efficacy' $(\mathrm{r}=0.37, \mathrm{p}<0.001)$ and 'team spirit' $(\mathrm{r}=0.36$, $\mathrm{p}<0.001$ ), whereas the personal resource of 'empathy' was nonsignificant and 'personality' was moderately negatively correlated for 'Neuroticism' $(r=-0.38, \mathrm{p}<0.001)$. 
Table 3

Scale reliabilities and means ( \pm standard deviations) on job demands, job resources, personal resources, work engagement, and healthy working.

\begin{tabular}{|c|c|c|c|c|c|}
\hline & Scale reliability & Overall $n=186$ & Nurses $n=146$ & Doctors $n=32$ & Bench mark \\
\hline Job demands & .74 & & & & \\
\hline Workload & n.a & $3.47( \pm 0.6)$ & $3.49( \pm 0.6)$ & $3.53( \pm 0.6)$ & \\
\hline Physical demand & n.a & $2.40( \pm 0.7)^{* *}$ & $2.54( \pm 0.7)^{*}$ & $1.84( \pm 0.7)$ & 2.0 \\
\hline Cognitive demand & n.a & $2.94( \pm 0.6)^{* *}$ & $2.95( \pm 0.6)$ & $2.98( \pm 0.7)$ & 2.5 \\
\hline Emotional demand & n.a & $2.51( \pm 0.6)^{* *}$ & $2.53( \pm 0.6)$ & $2.57( \pm 0.7)$ & 1.8 \\
\hline \multicolumn{6}{|l|}{ Job resources } \\
\hline Social support & .76 & $3.73( \pm 0.8)$ & $3.79( \pm 0.7)$ & $3.55( \pm 0.8)$ & 3.5 \\
\hline Feedback & .77 & $2.32( \pm 0.6)^{* *}$ & $2.30( \pm 0.7)$ & $2.36( \pm 0.6)$ & 2.7 \\
\hline Autonomy & .87 & $2.53( \pm 0.7)^{* *}$ & $2.53( \pm 0.7)$ & $2.34( \pm 0.8)$ & 2.9 \\
\hline Communication & .71 & $3.14( \pm 0.6)$ & $3.11( \pm 0.6)$ & $3.17( \pm 0.7)$ & 3.3 \\
\hline Team efficiency & .80 & $3.37( \pm 0.7)$ & $3.37( \pm 0.7)$ & $3.41( \pm 0.7)$ & 3.5 \\
\hline Team spirit & .85 & $3.88( \pm 0.7)$ & $3.99( \pm 0.7)$ & $3.53( \pm 0.7)$ & 3.8 \\
\hline \multicolumn{6}{|l|}{ Personal resources } \\
\hline Empathic ability & .73 & & & & \\
\hline Cognitive empathy & .87 & $3.95( \pm 0.6)$ & $4.00( \pm 0.6)$ & $4.02( \pm 0.6)$ & 4.0 \\
\hline Emotional empathy & .65 & $3.03( \pm 0.5)^{* *}$ & $3.05( \pm 0.4)$ & $3.04( \pm 0.5)$ & 3.8 \\
\hline Perspective taking & n.a & $2.67( \pm 0.4)$ & $2.68( \pm 0.4)$ & $2.73( \pm 0.3)$ & \\
\hline ICU-specific & .58 & $2.27( \pm 0.5)$ & $2.30( \pm 0.5)$ & $2.16( \pm 0.5)$ & \\
\hline \multicolumn{6}{|l|}{ Personality factors } \\
\hline Neuroticism & .83 & $2.34( \pm 0.6)$ & $2.30( \pm 0.6)$ & $2.32( \pm 0.5)$ & 2.5 \\
\hline Extraversion & .80 & $3.62( \pm 0.5)$ & $3.64( \pm 0.5)$ & $3.61( \pm 0.6)$ & 3.6 \\
\hline Openness & .76 & $3.82( \pm 0.5)^{* *}$ & $3.76( \pm 0.5)^{*}$ & $4.11( \pm 0.6)$ & 3.4 \\
\hline Agreeableness & .70 & $3.93( \pm 0.4)$ & $3.95( \pm 0.4)$ & $3.87( \pm 0.5)$ & 3.9 \\
\hline Conscientiousness & .78 & $3.98( \pm 0.4)$ & $3.99( \pm 0.4)$ & $4.00( \pm 0.4)$ & 3.8 \\
\hline \multicolumn{6}{|l|}{ Work engagement } \\
\hline Vigor & .86 & $3.53( \pm 0.7)$ & $3.51( \pm 0.6)$ & $3.70( \pm 0.6)$ & 3.7 \\
\hline Dedication & .89 & $3.87( \pm 0.7)^{* *}$ & $3.83( \pm 0.7)^{*}$ & $4.11( \pm 0.6)$ & 3.5 \\
\hline Absorption & .82 & $2.83( \pm 0.7)^{* *}$ & $2.74( \pm 0.6)^{*}$ & $3.26( \pm 0.6)$ & 3.4 \\
\hline \multicolumn{6}{|l|}{ Healthy working } \\
\hline Health symptoms & n.a & $1.76( \pm 1.0)$ & $1.71( \pm 1.0)$ & $1.81( \pm 1.0)$ & \\
\hline Work satisfaction & n.a & $3.97( \pm 0.7)$ & $3.97( \pm 0.7)$ & $4.00( \pm 0.8)$ & \\
\hline Team commitment & n.a & $3.89( \pm 0.7)$ & $3.90( \pm 0.6)$ & $3.94( \pm 0.7)$ & \\
\hline Institute commitment & n.a & $3.30( \pm 0.7)$ & $3.24( \pm 0.7)$ & $3.41( \pm 0.9)$ & \\
\hline Intention to leave & n.a & $1.76( \pm 1.0)$ & $1.75( \pm 0.9)$ & $1.81( \pm 1.1)$ & 2.2 \\
\hline Self-distancing & .74 & $1.65( \pm 0.5)$ & $1.70( \pm 0.5)^{*}$ & $1.51( \pm 0.4)$ & 1.5 \\
\hline
\end{tabular}

n.a not applicable.

* Difference is significant at 0.05 level (2-tailed) between nurses and doctors.

Difference is significant at 0.05 level (2-tailed) overall respondents compared to benchmark.

a General Dutch employees served as benchmark. Cognitive and emotional empathy were compared to a benchmark of general healthcare practitioners.

Table 4

Model summary of multiple linear regression analysis on work engagement.

\begin{tabular}{|c|c|c|c|}
\hline & $\beta( \pm S E)$ & $95 \% \mathrm{CI}$ & $\mathrm{P}$ \\
\hline \multicolumn{4}{|c|}{ Model $1, \mathrm{r}^{2}=0.341$, adjusted $\mathrm{r}^{2}=0.32, \mathrm{p}=0.001$} \\
\hline Team efficacy & $0.14( \pm 0.06)$ & $0.05 ; 0.28$ & 0.006 \\
\hline Team spirit & $0.13( \pm 0.06)$ & $0.01 ; 0.24$ & 0.029 \\
\hline Agreeable personality & $0.35( \pm 0.09)$ & $0.08 ; 0.42$ & 0.004 \\
\hline Conscientious personality & $0.21( \pm 0.08)$ & $0.09 ; 0.42$ & 0.003 \\
\hline Emotionally unstable personality & $-0.23( \pm 0.07)$ & $-0.34 ;-0.09$ & 0.001 \\
\hline \multicolumn{4}{|c|}{ Model 2, $\mathrm{r}^{2}=0.407$, adjusted $\mathrm{r}^{2}=0.38, \mathrm{p}=0.001$} \\
\hline \multicolumn{4}{|l|}{ Step 1} \\
\hline Team efficacy & $0.09( \pm 0.06)$ & $0.04 ; 0.37$ & 0.016 \\
\hline Team spirit & $0.09( \pm 0.06)$ & $-0.00 ; 0.33$ & 0.055 \\
\hline Agreeable personality & $0.20( \pm 0.08)$ & $-0.26 ; 0.01$ & 0.075 \\
\hline Conscientious personality & $0.16( \pm 0.08)$ & $-0.03 ; 0.22$ & 0.144 \\
\hline Emotionally unstable personality & $-0.12( \pm 0.07)$ & $-0.03 ; 0.21$ & 0.133 \\
\hline \multicolumn{4}{|l|}{ Step 2 , forced entry } \\
\hline ICU-specific & $-0.29( \pm 0.08)$ & $-0.44 ;-0.14$ & 0.001 \\
\hline Resilience & $0.03( \pm 0.07)$ & $-0.11 ; 0.17$ & 0.661 \\
\hline Social support & $0.02( \pm 0.06)$ & $-0.10 ; 0.14$ & 0.721 \\
\hline Autonomy & $0.06( \pm 0.05)$ & $-0.04 ; 0.15$ & 0.254 \\
\hline
\end{tabular}

Abbreviations: SE (standard error), CI (confidence interval), P (p-value, significant at 0.05 level).

In all ICU professionals, the personality traits showed significant correlations to 'work engagement' and the subscales of 'vigour', 'dedication' and 'absorption'. Mean 'cognitive empathy' correlated weakly to 'work engagement' $(r=0.18, \mathrm{p}<0.05)$. How- ever, neither 'emotional empathy' and 'perspective-taking', nor the 'ICU-specific' items, were statistically significant. The model summary of multiple linear regression analysis on work engagement is shown in Table 4. Highly work-engaged respondents were more 
likely to experience good 'team efficacy' ( $\beta=0.14, \mathrm{p}=0.01$ ), to feel higher 'team spirit' $(\beta=0.13, \mathrm{p}=0.03)$, to be more 'conscientious' ( $\beta=0.21, \mathrm{p}=0.001)$, to be more 'agreeable' $(\beta=0.35, \mathrm{p}=0.001)$, and to have an emotionally stable personality ('neuroticism') $(\beta=-0.23$, $\mathrm{p}=0.001$ ). After using a stepwise method with forced entry of all predictors simultaneously, the most confined multiple linear regression model was found to have an explained variance of $34 \%$ (adjusted $r^{2}=0.32$ ).

Furthermore, no moderation effect was found for the personality factors of conscientiousness, agreeableness or neuroticism in the relationship between job demands and work engagement. Although the conditional effects of workload moderated by the personality factors were found to be statistically significant for team efficacy and team spirit, no interaction terms produced an effect on workload. ${ }^{30}$

\section{Discussion}

The overall aim of this study was to explore the relationships between job demands, personal resources and work engagement among ICU professionals. Job demands were negatively related to work engagement; however, no significant relationship was found between personal resources and work engagement.

The results showed that there were relatively high physical, cognitive and emotional job demands in the ICU; in contrast, these job demands were not found to be problematic for most respondents. It seemed that a workload with a high emotional burden is acknowledged as an integral part of ICU work. This normalization of emotional demands was also reflected by minimally reported symptoms of stress in the current study. Both ICU nurses and intensivists responded within normal limits for vigour and were highly dedicated to their jobs. A recent longitudinal study similarly noted relatively high or average levels of work engagement. ${ }^{31}$ In the current study, a low absorption in nurses was identified. This result might be explained by the work situation, including including the demands of multi-tasking, facing sometimes hectic and life-threatening demands, constant alarms, divided attention and requests for help or information that all pose challenges to workflow in the ICU. Thus, it might be difficult to experience flow while working in an ICU.

Overall, the relationships between the independent variables (i.e., job demands and job resources), and the primary outcome (i.e., work engagement) confirmed the findings in previous studies. ${ }^{16,18,20,29}$ As outlined in the introduction, it was assumed that job demands were negatively related to work engagement (Hypothesis 1). The results partly supported this assumption, in that cognitive demands for intensivists and emotional demands for ICU nurses were negatively related to the work engagement. Therefore, the level of work engagement decreased if higher physical, cognitive and emotional demands were experienced. Job resources were assumed to relate positively with work engagement (Hypothesis 2). The results largely supported this assumption, since positive relationships between job resources and work engagement were found for both intensivists and ICU nurses. The level of work engagement increased when experiencing higher team spirit, team efficacy, social support, autonomy, performance feedback, and better peer communication. These findings were consistent with recent research, indicating that employees with sufficient job resources will feel important to the organization, optimistic about their future and an increased sense of self-efficacy. ${ }^{18,20}$ Such findings suggest that ICU professionals are more engaged and better able to focus on the provision of excellent care where good team spirit and optimal team efficacy prevail. .,32 $^{1,32}$

The importance of personal resources becomes clear when considering that employees working in the one unit are exposed to the same organizational and job-related circumstances, may experience different reactions to work-related stress and different levels of work engagement. Personal resources, such as personality traits, might partly explain these differences. ${ }^{33}$ The personality traits of the ICU professionals reflected the wider population. ${ }^{26,34}$ As expected, the traits of agreeableness and conscientiousness had positive main effects while neuroticism had a negative main effect (Hypothesis 3). However, none of these personal resources had a moderating effect on the relationship between job demands and work engagement (Hypothesis 3a), nor on the relationship between job resources and work engagement (Hypothesis 3b). The relationships between neuroticism on both work engagement and emotional health showed moderately negative correlations. These associations could be explained by the general likelihood of persons with higher levels of neuroticism to experience negative emotions or the probability that they will perceive their environment as more stressful than can be managed by their poor coping abilities. For instance, neuroticism has been linked to burnout in ICU nurses, ${ }^{35}$ as they view their work as being more stressful and they are less likely to seek help from friends or colleagues than emotional stable colleagues. This finding is consistent with studies on work-related stress in physicians. ${ }^{36}$ Contrary to the negative impact of neuroticism, the personality traits of agreeableness and conscientiousness contributed substantially and positively to work engagement. This the findings inform an ideal personality profile, in which ICU professionals will feel important to the organization, optimistic about their future, have an increased sense of self-efficacy, and are particularly responsive with a compassionate attitude towards other persons. ${ }^{37}$ Although the data mostly support the hypotheses, it might be argued to be more about the hospital culture than the ICU professionals themselves. ${ }^{38}$ A study on team climate suggested a positive relationship between a team-satisfaction-oriented culture and a low level of work-related stress. ${ }^{39}$ Since team spirit, team efficacy, and social support scored high in the current study, these findings on team culture might also be reflective of the high scores on work engagement.

ICU professionals showed remarkably low scores in emotional empathy, whereas their cognitive empathy matched those of general healthcare providers. Consequently, they understood the patients and relatives but kept themselves at a certain emotional distance. This tendency might be interpreted as being a protective reaction for one's own emotional health. ${ }^{40}$ Excessive empathy also has another side, leading to over-engagement, which can be damaging to the professionals' well-being. ${ }^{41}$ Revealing diminished emotional empathy is of the utmost importance in the performance of intensive and invasive treatments. ${ }^{5,42}$ The study findings suggest that ICU professionals used this balanced emotional coping strategy of distancing to deal with the emotional demands of their work environment.

In contrast to the previously reported work-related stress levels and prevalence of burnout, in this study, a high work engagement and low levels of the symptoms of stress were observed. Apparently, ICU professionals learned to cope with the stress of their work environment. In addition, resilience might also decrease the development of work-related stress in ICU professionals. ${ }^{43}$ Resilience is considered as the ability to maintain mental equilibrium, which is an active and flexible process of the adaptation to life changes, and operates as a protective factor against psychological distress and mental disorders. ${ }^{44}$ It is closely related to vigour, energy, motivation, and personal strength, which enable one to cope with stressful situations when confronted with danger or suffering. Subsequently, this ability to adopt and self-manage the challenging situations in an ICU might positively influence the emotional health of clinical professionals. 


\subsection{Practical implications}

If ICU professionals have personality traits that particularly suited to the role, this might result in improved workplace efficiency, work engagement and staff retention. Agreeable, conscientious and emotionally stable persons might personify the characteristics needed to implement the appropriate interventions and coping strategies that address workplace stressors. Accordingly, providing management team input to create a stable and engaged team may help address the high emotional demands of the ICU and improve the quality of care improve. However, a team composed of professionals with the 'right' profile is difficult to establish and maintain. Due to work-related stress, even the most resilient employees might potentially and gradually lose their positive mind-setting and experience challenges to their commitment and work engagement. Therefore, strategies that support ICU-professionals are needed to underscore the importance of their (emotional) health. ${ }^{4}$

\subsection{Study limitations}

There are certain limitations that need to be acknowledged in the present study. First, because of the cross-sectional design, an interpretation of the causality in the relationships between variables is not possible. Longitudinal studies are needed to understand the causal and reciprocal relationships between the constructs and to validate the findings over time. Second, some of the nonresponses might have been due to apathy, a negative work attitude or even burnout. It could be speculated that emotionally healthy professionals had a greater tendency to participate, leading to more optimistic results and a 'healthy worker effect'. Third, the data were obtained exclusively by self-report questionnaires, which could have led to socially desirable answers and presents common method variance problems. ${ }^{45}$ Approaches other than self-report have rarely been applied to measure the used constructs. ${ }^{46}$ Fourth, the items measuring empathy were adapted to the specific culture of the ICU (i.e., some linguistic changes were made). Therefore, more research on empathy using cross-cultural and psychometrically validated instruments is needed. Finally, the data were collected exclusively from a convenience sample of professionals working in the ICUs of a single university hospital; thus, generalization of the study results is not warranted. Future research plans have been made to replicate this study in various clinical settings and in an international context.

\section{Conclusions}

Work engagement, which recognizes positively labelled elements, is the counterbalance to work-related stress. The relatively high workload in ICUs, coupled with an especially high emotional burden, may be acknowledged as an integral part of ICU work. This workload does not affect the level of work engagement, which was high for both intensivists and nurses despite the known high job demands. For these respondents the job demands seemed manageable. It also appeared that, in general, personal resources were considered sufficient. Although there was no influence of empathy on work engagement, the results of this study suggest that ICU professionals understand the feelings of patients and their families but remain at a certain emotional distance. This finding may be interpreted as a protective reaction for their own emotional health; however, specific factors that contribute to a healthy and successful work life among ICU professionals require further exploration.

\section{Author contributions}

All authors have agreed on the final version and meet at least one of the following criteria:
1) Substantial contributions to conception and design (MvM, $\mathrm{MN}, \mathrm{WS})$, acquisition of data (MvM) or analysis (MvM, MN) and interpretation of data (MvM, MN, JB, WS, EK);

2) Drafting the article (MvM) or revising it critically for important intellectual content (MN, JB, WS, EK).

3) Final approval of the version to be submitted (MvM, MN, JB, WS, EK);

4) Agreement to be accountable for all aspects of the work in ensuring that questions related to the accuracy or integrity of any part of the work are appropriately investigated and resolved (MvM, $\mathrm{MN}, \mathrm{JB}, \mathrm{WS}, \mathrm{EK})$.

\section{Disclosure statement}

The authors declare that they have no competing interests. No financial support declared. This research did not receive any specific grant from funding agencies in the public, commercial, or not-forprofit sectors.

\section{References}

1. Moss M, Good VS, Gozal D, Kleinpell R, Sessler CN. An official critical care societies collaborative statement-burnout syndrome in critical care health-care professionals: a call for action. CHEST 2016;150(1):17-26.

2. Sprung CL, Cohen R, Marini JJ. Excellence in intensive care medicine. Crit Care Med 2016;44(1):202-6.

3. Donchin Y, Seagull FJ. The hostile environment of the intensive care unit. Curr Opin Crit Care 2002;8(4):316-20.

4. van Mol MMC, Kompanje EJO, Benoit DD, Bakker J, Nijkamp MD. The prevalence of compassion fatigue and burnout among healthcare professionals in intensive care units: a systematic review. PLoS One 2015;10(8):e0136955.

5. van Mol MMC, Brackel M, Kompanje EJO, Gijsbers L, Nijkamp MD, Girbes ARJ, et al. Joined forces in person-centered care in the intensive care unit: a case report from the Netherlands. J Compassionate Health Care 2016;3(1):1.

6. Embriaco N, Papazian L, Kentish-Barnes N, Pochard F, Azoulay E. Burnout syndrome among critical care healthcare workers. Curr Opin Crit Care 2007; 13(5):482-8.

7. Epp K. Burnout in critical care nurses: a literature review. Dynamics 2012;23(4):25-31.

8. Leiter MP, Bakker AB, Maslach C. Burnout at work: a psychological perspective. New York: Psychol Press; 2014. ISBN 9781848722286.

9. Aiken LH, Clarke SP, Sloane DM, Sochalsku J, Silber JH. Hospital nurse staffing and patient mortality, nurse burnout, and job dissatisfaction. JAMA 2002;288(16):1987-93.

10. Castle NG, Engberg J. Staff turnover and quality of care in nursing homes. Med Care 2005;43(6):616-26.

11. Leiter MP, Maslach C. Nurse turnover: the mediating role of burnout. J Nurs Manage 2009;17(3):331-9.

12. Viotti S, Converso D, Loera B. Job satisfaction, job burnout and their relationships with work' and patients' characteristics: a comparison between intensive care units (ICU) and not-intensive care units (non-ICU). G Ital Med Lav Ergon 2012;34(2 Suppl. B):B52-60.

13. Meynaar IA, van Saase JLCM, Feberwee T, Aerts TM, Bakker J, Thijsse W. Burnout among dutch intensivists. Neth J Crit Care 2015;24(1):12-7.

14. Csikszentmihalyi M, Seligman ME. Positive psychology: an introduction. Am Psychol 2000;55(1):5-14.

15. Fredrickson BL. The role of positive emotions in positive psychology: the broaden-and-build theory of positive emotions. Am Psychol 2001;56(3):218.

16. Schaufeli WB. Engaging leadership in the job demands-resources model. Career Dev Int 2015;20(5):446-63.

17. Bakker AB, Schaufeli WB, Leiter MP, Taris TW. Work engagement: an emerging concept in occupational health psychology. Work Stress 2008;22(3):187-200.

18. Schaufeli WB, Taris TW. A critical review of the job demands-resources model: implications for improving work and health. In: Bridging occupational, organizational and public health. Springer; 2014. p. 43-68.

19. Bakker AB, Demerouti E, Taris TW, Schaufeli WB, Schreurs PJ. A multigroup analysis of the job demands-resources model in four home care organizations. Int J Stress Manage 2003;10(1):16.

20. Xanthopoulou D, Bakker AB, Demerouti E, Schaufeli WB. The role of personal resources in the job demands-resources model. Int J Stress Manage 2007; 14(2):121

21. Seppälä P, Hakanen J, Mauno S, Perhoniemi R, Tolvanen A, Schaufeli W. Stability and change model of job resources and work engagement: a seven-year threewave follow-up study. Eur J Work Organ Psychol 2015;24(3):360-75.

22. Geuens N, Braspenning M, van Bogaert P, Franck E. Individual vulnerability to burnout in nurses: the role of type $\mathrm{D}$ personality within different nursing specialty areas. Burnout Res 2015;2(2):80-6.

23. Central Committee on Research Involving Human Subjects (CCMO). Available from: http://www.ccmo.nl/en/non-wmo-research [cited 27 April 2017]. 
G Model

AUCC-375; No. of Pages 8

8

M.M.C. van Mol et al. / Australian Critical Care $x x x$ (2017) $x x x-x x x$

24. van Veldhoven M, de Jonge J, Broersen S, Kompier M, Meijman T. Specific relationships between psychosocial job conditions and job-related stress: a three-level analytic approach. Work Stress 2002;16(3):207-28.

25. Hooftman W, Houtman I, Kwantes J. Netherlands EWCO CAR on working conditions in the retail sector- national contribution. European Foundation for the Improvement of Living and Working Conditions 2012.

26. Costa Jr P, McCrae RR. Neo personality inventory-revised (neo-pi-r) and neo fivefactor inventory (neo-ffi) professional manual. Odessa, FL: Psychol Assessment Resources; 1992.

27. Hojat M, Gonnella JS, Nasca TJ, Mangione S, Vergare M, Magee M. Physician empathy: definition, components, measurement, and relationship to gender and specialty. Am J Psychol 2002;159:1563-9.

28. Schaufeli WB, Baker AB, Salanova M. The measurement of work engagemont with a short questionnaire a cross-national study. Educ Psychol Meas 2006; 66(4):701-16.

29. Schaufeli WB, Baker AB. Job demands, job resources, and their relationship with burnout and engagement: a multi-sample study. J Organ Behav 2004;25(3):293-315

30. Field. Discovering statistics using SPSS. fourth edition London: SAGE Publications; 2014. ISBN 9781446249185.

31. Mäkikangas A, Kinnunen U, Feldt T, Schaufeli W. The longitudinal development of employee well-being: a systematic review. Work Stress 2016:1-25.

32. Pastores SM. Burnout syndrome in ICU caregivers: time to extinguish! CHEST 2016;150(1):1-2.

33. Alarcon G, Eschleman KJ, Bowling NA. Relationships between personality variable and burnout: a meta-analysis. Work Stress 2009;23(3):244-63.

34. Costa PT, McCrae RR. Normal personality assessment in clinical practice: the NEO personality inventory. Psychol Assess 1992;4(1):5.

35. Burgess L, Irvine F, Wallymahmed A. Personality, stress and coping in intensine care nurses: a descriptive exploratory study. Nurs Crit Care 2010;15(3): 129-40.
36. McManus I, Keeling A, Price E. Stress, burnout and doctors' attitudes to work are determined by personality and learning style: a twelve year longitudinal study of UK medical graduates. BMC Med 2004;2(1):1.

37. Kennedy B, Curtis K, Waters D. Is there a relationship between personality and choice of nursing specialty: an integrative literature review. BMC Nuts 2014;13(1):1.

38. Baker AB, Le Blanc PM, Schaufeli WB. Burnout contagion among intensive care nurses. J Adv Nurs 2005;51(3):276-87.

39. Guide B, González-Romá V. Climate and cultural aspects in intensive care units. Crit Care 2011;15(6):312.

40. Bühler KE, Land T. Burnout and personality in intensive care: an empirical study. Hosp Top 2003;81(4):5-12.

41. Santos A, Chamber MJ, Castanheira F. Relational job characteristics and nurses' affective organizational commitment: the mediating role of work engagement. J Adv Nurs 2016;72(2):294-305.

42. Kompanje EJO, van Mol MMC, Nijkamp MD. 'I just have admitted an interesting sepsis'. Do we dehumanize our patients? Intensive Care Med 2015;41(12):2193-4.

43. Mealer M, Jones J, Newman J, McFann KK, Rothbaum B, Moss M. The presence of resilience is associated with a healthier psychological profile in intensive care unit (ICU) nurses: results of a national survey. Int J Nurs Stud 2012;49(3):292-9.

44. Montero-Marin J, Tops M, Manzanera R, Demarzo MMP, de Mon MÁ, GarcíaCampayo J. Mindfulness, resilience, and burnout subtypes in primary care physicians: the possible mediating role of positive and negative affect. Front Psychol 2015:6.

45. Podsakoff PM, MacKenzie SB, Lee JY, Podsadoff NP. Common method biases in behavioral research: a critical review of the literature and recommended remedies. J App Psychol 2003;88(5):879.

46. Mäkikangas A, Kinnunen U, Feldt T. Self-esteem, dispositional optimism, and health: evidence from cross-lagged data on employees. J Res Prs 2004;38(6):556-75.

Please cite this article in press as: van Mol MMC, et al. Counterbalancing work-related stress? Work engagement among intensive care professionals. Aust Crit Care (2017), http://dx.doi.org/10.1016/j.aucc.2017.05.001 